\title{
Does the backrest shape of the wheelchair influence the asymmetric posture of patients with hemiparesis? A single institution pilot study
}

\author{
Atsuki Ukita $^{1 *}$, Masayuki Abe ${ }^{1}$, Masaharu Nikaido ${ }^{1}$, Katsuaki Arisawa ${ }^{1}$, Tatsuo Hatta ${ }^{2}$ and Hirotoshi Kishigami ${ }^{2}$ \\ ${ }^{1}$ Social Medical Corporation Hokuto, Tokachi Rehabilitation Center, Obihiro, Japan \\ ${ }^{2}$ Japan Health Care College, Eniwa, Japan
}

\begin{abstract}
We have previously reported the effect of wheelchair with a unique backrest shape with pelvic and thoracic support (P-WC) on healthy individuals. However, the actual effect of $\mathrm{P}-\mathrm{WC}$ on real users is still unclear. Therefore, the purpose of this study was to investigate the effect of different backrest shapes on asymmetric seated posture and pressure points in patients with hemiplegia. We compared a typical wheelchair with a flat backrest (T-WC) to P-WC. Ten subjects with hemiparesis were analyzed. Outcome measures were body alignment angles and pressure distributions of the supporting surfaces. The total seat pressure decreased $(\mathrm{p}<0.01)$ and total back pressure increased $(\mathrm{p}<0.05)$, in P-WC compared with T-WC. The head-neck was more upright $(\mathrm{p}<0.05)$ in P-WC than in T-WC. Moreover, the center of pressure was located in the middle of both the seat and backrest $(p<0.05)$, and the high unilateral pressure around the ischial tuberosity was dispersed $(p<0.05)$ in P-WC. In conclusion, the backrest shape of the P-WC contributes to reducing postural asymmetry. These results highlight the importance of the shape of the wheelchair backrest for patients with hemiparesis.
\end{abstract}

\section{Introduction}

Stroke, a serious health problem worldwide, continues to rank high among death causes [1,2]. Many patients with post-stroke hemiparesis have balance deficits and natural decreases in muscle strength and age-related endurance $[3,4]$. Specifically, stroke patients usually place more weight unilaterally $[5,6]$ and find balancing when standing/ sitting difficult $[7,8]$. Moreover, increased postural sway worsens these balance difficulties [9]. Previous cross-sectional studies of sitting balance suggest a reduced voluntary bilateral trunk performance in stroke patients $[10,11]$. Furthermore, voluntary and involuntary muscle activations are impaired predominantly on the paretic side [12,13], resulting in high rates of post-rehabilitation wheelchair dependence [14].

Wheelchairs are very important assistive devices [15,16] and are widely used by people with mobility challenges. Although the general shape of a typical wheelchair (hereafter, T-WC; flat support surface and linear backrest post) is often selected, making individual adjustments is difficult, this configuration is not suitable for those with postural sitting problems [17]. In a study of 150 wheelchair users, $68 \%$ of users reported discomfort, pain, or other structural incompatibility [18]. In a survey of elderly wheelchair users residing in nursing homes or care facilities, more than $50 \%$ had problems with wheelchair fit (e.g., poor posture and discomfort) $[19,20]$.

In clinical situations, wheelchair users, and especially patients with stroke, often have a tilted, slumped, and asymmetric posture [21]. Previous studies have demonstrated that the postural stability of the trunk affects sitting balance and upper-limb function [22,23]. Although balancing in the sitting position is not, in itself a functional activity as balancing in the standing position is, proper seated posture is required for basic daily activities, such as eating and dressing [24,25].
Therefore, achieving a symmetrical sitting posture would be beneficial for hemiparesis patients. The use of a cushion improves post-stroke asymmetry [26]; however, there is little evidence demonstrating how wheelchair configuration affects post-stroke asymmetry. A few studies have emphasized the importance of pelvic and thoracic support belts to maintain a proper seated posture with little burden $[27,28]$.

We developed a wheelchair with a unique backrest shape and support belt design to support the pelvis and thorax (hereafter, pelvissupported wheelchair; P-WC). The backrest of P-WC effectively promotes upright alignment of the head and neck in healthy individuals and the elderly $[29,30]$. However, the P-WC's potential to correct asymmetrical posture in patients with hemiparesis has not yet been investigated. Therefore, we aimed to investigate the effect of the new backrest design on asymmetric wheelchair-seated posture using T-WC and P-WC.

\section{Methods}

\section{Subjects}

Ten subjects with post-stroke hemiparesis ( 5 men, 5 women) were recruited. Disease severity of post-stroke patients was evaluated using Brunnstrom's stages (1-7 scale), which assessed motor control

Correspondence to: Atsuki Ukita, Social Medical Corporation Hokuto, Tokachi Rehabilitation Center, Kisen 2-1, Inadacyou, Obihiro, Hokkaido, 080-0033, Japan, Tel: +81-15-567-6820; Fax: +81-15-567-6821; E-mail: a.ukita19@gmail.com

Key words: hemiparesis, posture, pressure, wheelchairs

Received: October 22, 2017; Accepted: November 11, 2017; Published: November 15, 2017 
[31]. Subjects who met the following selection criteria were recruited: medically stable physical condition, ability to move to the wheelchair or bed with little assistance, and ability to maintain sitting posture for $>30 \mathrm{~min}$. The exclusion criterion was the presence of dementia, which could affect the judgment of voluntarily participating in the study. The study was approved by the institutional review board of Hokkaido University Graduate School of Health Sciences (approval number; 1344), Japan, and all subjects provided written informed consent.

\section{Wheelchairs}

The present study used two wheelchair types. Both had a sling seat and backrest comprising flexible upholstery material(s) and a tension-adjustment function for postural support. Figure 1 shows the difference in backrest shapes between T-WC (NAH-446W, Nissin Medical Industries, Japan) and P-WC (NAH-521W, Nissin Medical Industries, Japan). P-WC was created using the sitting theory proposed by Nishimura $[27,28]$. It has three tension-adjustable Velcro belts, and the backrest posts incline backward in three stages. The three belts support the pelvis (PL), lower thorax (LT), and upper thorax (UT). The PL support belt comprises two Velcro belts as well as a hook-and-loop fastener and can be set at one of the several pelvic angles.

The upper end of the PL support belt was positioned at the iliac crest, and the body of the belt was set to support L4-L5. Therefore, the PL support belt supported the pelvis from both the side and back. The LT support cross belts run diagonally from the top of the PL support belt to the lower end of the UT support belt and support the thorax diagonally from below. The intersection of the cross belt was arranged 1 inch back from the PL support belt. The UT support belt was adjusted to avoid pressing into the scapula and thorax. This belt supported users when sitting in a relaxed posture.

On the P-WC, the aforementioned tension adjustments were made before conducting the experiment. The belts on the T-WC were stretched tightly to reproduce the flat support surface. Individual settings during the experiment were unchanged (Figure 1).

To facilitate the body alignment measurement from the side, manual, attendant-controlled wheelchairs with small wheels and flipup side guards were used. The seat and backrest planes were $400 \times$ $400 \mathrm{~mm}^{2}$. The same seat cushion was used to standardize seat surface conditions in both wheelchairs. The only difference between the two wheelchairs was the backrest shape.

\section{Experimental postural setting}

Both types of wheelchairs were equipped with pressure-mapping mats. Each subject was seated in both types of wheelchairs in a random sequence. Subjects were seated with their pelvis as far back as possible on the seat. This seated posture is often found in hospital settings in Japan. Each wheelchair was adjusted for each subject as previously described, so that subjects' thighs were in a horizontal position and their line of vision was fixed horizontally [32,33]. Markers were attached by physical and occupational therapists to each body segment of the subjects after they were seated. The therapists then carefully checked the left and right attachment points. To minimize discomfort, a circular seal, $10 \mathrm{~mm}$ in diameter, was used for the facial attachment; retro-reflective markers 12-20 $\varphi$ were used at the other locations. After the markers were attached, subjects were instructed to sit naturally and remain motionless during the test.

\section{Pressure measurements}

The Force Sensing Array (FSA) system was used to collect pressure data at the seat and backrest interfaces. The FSA (Vista Medical Ltd.,
Canada) is a $430 \times 430 \mathrm{~mm}^{2}$ flexible pressure mat with 256 sensors covering the entire contact area between the subject and the wheelchair. The measured pressure range was $0-200 \mathrm{mmHg}$ and the accuracy of the pressure measurement was $\pm 10 \%$ of the full scale [34]. Each cell size was $26.9 \mathrm{~mm}$. Sampling rates of FSA were set at $5 \mathrm{~Hz}$ and calibrated prior to the experiment [35]. The front edge of the mat was aligned with the front part of the seat surface and with the underside of the backrest. The FSA is commonly used in clinical settings for pressure measurements [36,37] and its reliability and repeatability in the same location and time, and the same operator and measurement surface condition have been confirmed [38]. After the subjects had been seated about $5 \mathrm{~min}$, pressure distribution in the back and seat was measured for approximately $1 \mathrm{~min}$. The maximum pressure, mean pressure, center of pressure, and sensing area were automatically calculated using the FSA software 4.0. From these values, the total pressure in both the back and seat was calculated.

The symmetry index (SI) was used to assess the differences in pressure distribution during sitting. To measure the pressure distribution from the left and right, the bilateral $3 \times 3$ pressure transducer data from the ischial tuberosity were processed. A SI of $0 \%$ represents equal pressures on both sides. The SI formula is shown below [26,37]:

Symmetry Index $(\%)=\left|\frac{\text { Variables }(\text { Paretic })-\text { Variables }(\text { Nonparetic })}{\text { Variables }(\text { Paretic })+\text { Variables }(\text { Nonparetic })}\right| \times 2 \times 100$

\section{Postural alignment measurement}

To measure head-neck alignment, we recorded wheelchairseated posture in the sagittal and frontal planes. Video images were analyzed for body segment inclination with respect to vertical using the Dartfish (Dartfish Ltd., Switzerland) software previously used in basic and clinical research for postural assessment $[39,40]$. The minimum angular resolution of the analyzer system is $0.1^{\circ}$.

The height of the video camera's lens center was set at the armrest height. The video camera that recorded the frontal plane was set in front of the wheelchairs, and the distance of the camera from the wheelchair was standardized at $3 \mathrm{~m}$, with both the subject and the wheelchair falling within the video frame. The video camera that recorded the sagittal plane was located just beside the wheelchair's arm support tip, and the distance of the camera from the wheelchair was standardized at $2 \mathrm{~m} 85 \mathrm{~cm}$.

Figure 2 shows the criteria for the measured angles. In the sagittal plane, the inclination angle of the head was defined as the angle between the vertical line and the line through the tragus of the ear and the outer canthus of the eye (a); the inclination angle of the neck was defined as the angle between the vertical line and the line through C7 and the tragus (b); and the inclination angle of the trunk was defined as the angle between the vertical line and the line through the greater trochanter and C7 (c) $[32,41]$.

In the frontal plane, the lateral inclination angle of the head was defined as the angle between the vertical line and the line through the glabella and the top of the chin (d); the lateral inclination angle of the neck was defined as the angle between the vertical line and the line through the top of the chin and the superior margin of the sternum (e); the lateral inclination angle of the trunk was defined as the angle between the vertical line and the line through the superior margin of the sternum and the xiphisternum (f); and the acromial tilt angle was defined as the angle between the horizontal line and the line through both acromions $(\mathrm{g})$. These angles were defined with reference to previous research [42]. 


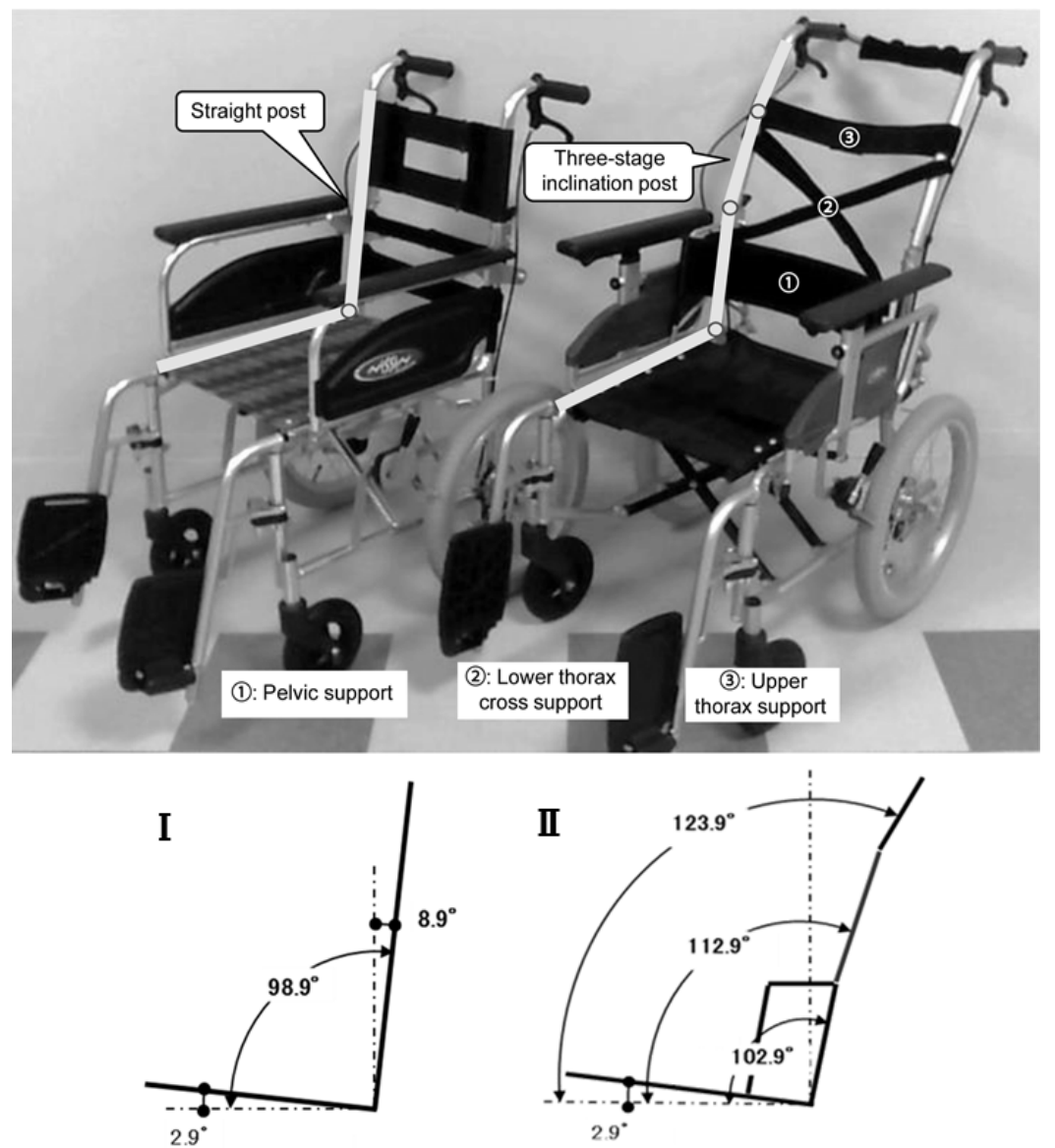

Figure 1. Difference in backrest shapes. Left: T-WC. Right: P-WC. The sling seat of the backrest was removed to standardize the experimental conditions. The seat angles are $2.9^{\circ}$ for both wheelchairs. I: The seat-backrest post angle of T-WC is $96^{\circ}$. II: The seat-backrest post angle of P-WC is $100^{\circ}$ for the $\mathrm{PL}, 110^{\circ}$ for the LT, and $121^{\circ}$ for the UT.

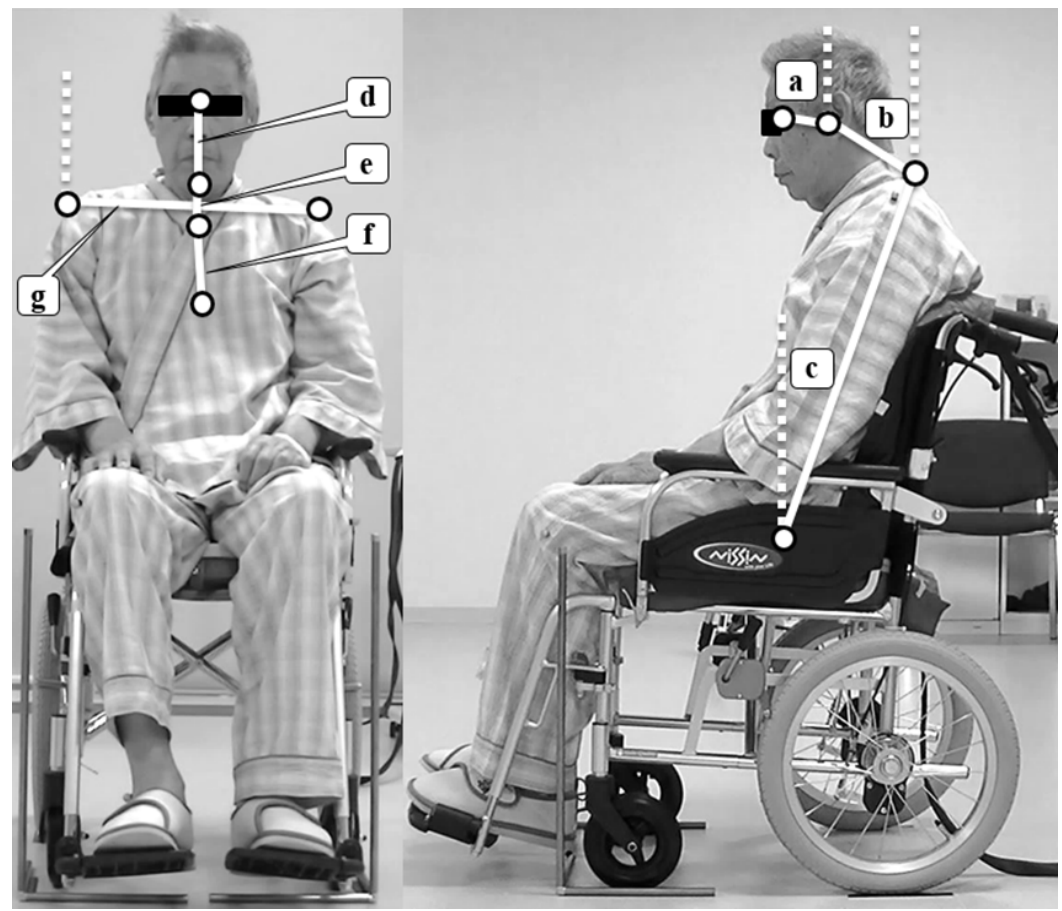

Figure 2. Angle criteria. a: Head inclination angle. b: Neck inclination angle. c: Trunk inclination angle. d: Head lateral inclination angle. e: Neck lateral inclination angle. f: Trunk lateral inclination angle. $\mathrm{g}$ : Acromial tilt angle. In the frontal plane, the vertical line is not described to facilitate observation with the exception of the acromial tilt angle. 


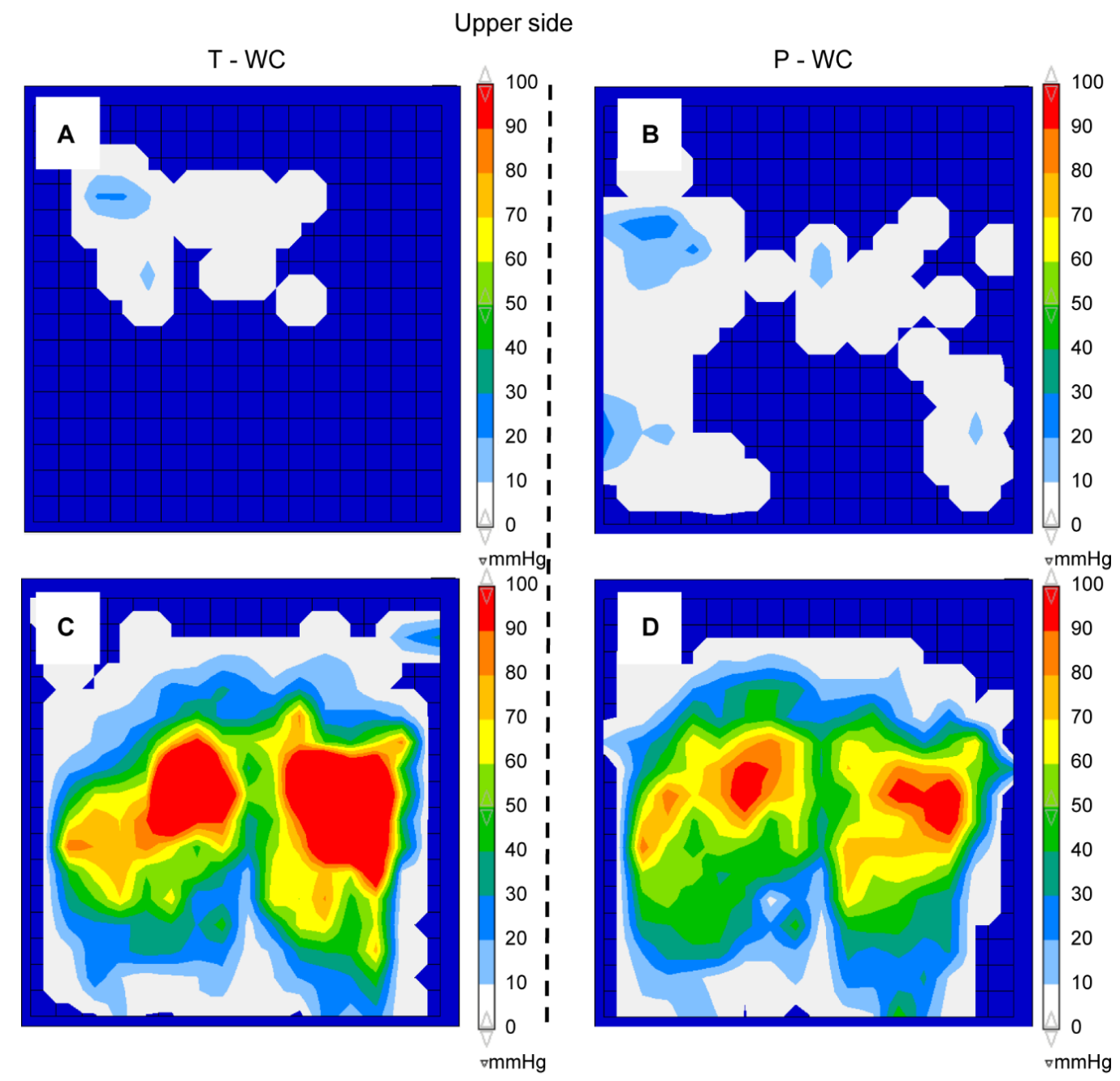

Front side

Figure 3. Typical example of pressure distribution. A: Backrest plane of T-WC. B: The backrest plane of P-WC. C: The seat plane of T-WC. D: The seat plane of P-WC.

\section{Statistical analysis}

SPSS (SPSS Inc., Chicago, USA.) version 22.0 for Windows was used in the data analysis. All data were expressed as medians and quartiles. The data obtained from the two chairs were compared using a Wilcoxon signed-rank test. A significance level of $p<0.05$ was used for all statistical comparisons.

\section{Results}

\section{Demographic data}

The subjects were all adults (age 67.1 19.54 years; weight $53.2 \pm$ $11.66 \mathrm{~kg}$; height $158.0 \pm 7.35 \mathrm{~cm}$ ) who developed hemiparesis after a stroke that was either a cerebral infarction or an intracerebral hemorrhage (Table 1).

\section{Pressure}

Figure 3 shows the typical pressure distribution of a subject with hemiparesis (case \#7). In P-WC, high pressure distribution around the ischial tuberosity was dispersed compared with that in T-WC. Moreover, in P-WC, the pressure distribution of the backrest extended further to the middle and lower part, and the size of the contact area to the right and left was also relatively large.
Table 1. Demographic and clinical data.

\begin{tabular}{|c|c|c|c|c|c|c|}
\hline No. & Disease & $\begin{array}{c}\text { Paretic } \\
\text { side }\end{array}$ & Gender & $\begin{array}{c}\text { Days since } \\
\text { stroke } \\
\text { onset }\end{array}$ & Brs(UE) & Brs(LE) \\
\hline 1 & CI & L & F & 58 & 4 & 3 \\
\hline 2 & CI & L & F & 118 & 5 & 3 \\
\hline 3 & ICH & L & F & 122 & 3 & 4 \\
\hline 4 & ICH & L & M & 77 & 4 & 4 \\
\hline 5 & CI & L & M & 30 & 4 & 5 \\
\hline 6 & ICH & L & M & 126 & 2 & 3 \\
\hline 7 & CI & R & F & 103 & 3 & 4 \\
\hline 8 & CI & R & M & 107 & 2 & 3 \\
\hline 9 & CI & R & F & 109 & 4 & 5 \\
\hline 10 & CI & R & M & 48 & 3 & 4 \\
\hline
\end{tabular}

CI: cerebral infarction; ICH: intracerebral hemorrhage; L: left; R:right; Brs: Brunnstrom stage; UE: upper extremity; LE: lower extremity

The pressure measurements are summarized in Table 2. In two patients, few (1-3) of the 256 FSA sensors exceeded $200 \mathrm{mmHg}$ of pressure, which is the measurement limit. In this case, we treated the sensor value as $200 \mathrm{mmHg}$. In P-WC, the total seat pressures were lower by a factor of approximately $0.8(\mathrm{p}<0.01)$ compared with those in T-WC, and the total backrest pressures increased by a factor of approximately $1.7(\mathrm{p}<0.05)$. The center of pressure of $\mathrm{P}-\mathrm{WC}$ was more 
centralized than T-WC for both support surfaces $(\mathrm{p}<0.05)$. The seat-toback ratio, in terms of total pressure, was 30:1 for T-WC and 15:1 for $\mathrm{P}$-WC, resulting in symmetry indices of $27.1 \%$ for T-WC and $13.5 \%$ for P-WC $(\mathrm{p}<0.05)$.

\section{Postural alignment}

The postural measurements performed in the sagittal and frontal planes are shown in Table 3. In general, posture of the subject with hemiparesis in the standard T-WC was slightly asymmetric. Angle differences between the paretic and non-paretic side were observed for neither T-WC nor P-WC.

In the frontal plane, $\mathrm{P}-\mathrm{WC}$ did not significantly improve any of the parameters compared with T-WC. In the sagittal plane, P-WC did not affect the head inclination angle, but it reduced the neck inclination angle $(\mathrm{p}<0.05)$ and increased the trunk inclination angle $(\mathrm{p}<0.01)$ on both sides, compared with T-WC. The results indicated that the patients leaned more into the backrest with less strain on their necks in $\mathrm{P}-\mathrm{WC}$ than in T-WC.

\section{Discussion}

In this study, we compared the static wheelchair-seated posture and pressure distribution of subjects with hemiparesis in the standard T-WC and new P-WC with a redesigned backrest. The newly arranged backrest generated significant differences in the total pressure, position of the center of pressure, and neck and trunk inclination angles.

On the backrest plane, the contact area including the pelvic region was significantly increased in P-WC compared with that in T-WC and the center of pressure of P-WC was more centralized than T-WC for both support surfaces. The orientation of the trunk is supported by somatosensory information [43]. The pelvis is the foundation of the spinal column and the tilt of the pelvis affects trunk alignment $[44,45]$. In $\mathrm{T}$-WC, the contact area of the trunk was narrow and there was no pressure reaction in the lower part of the backrest including the pelvis. Possibly as a consequence of this, somatosensory information becomes poor due to non-contact of the pelvis, which may promote head or trunk inclination. In contrast, the backrest post of P-WC is inclined backward in three stages, with a $100^{\circ}$ wide-angle design in the pelvic region, compared with $96^{\circ}$ for the seat-backrest post angle of T-WC. The backrest post angle of P-WC provides diagonal support from below to receive the weight of the trunk. This angle, and adjustable feature of the support belts jointly offer a large contact area and supports each area of the trunk, including the pelvis. This expansion of contact area leads to an increase in somatosensory information and would contribute to the P-WC's centralizing the center of pressure by ensuring lateral back stability, including the pelvis and trunk.

On the seat plane of $\mathrm{P}-\mathrm{WC}$, the high pressure was dispersed by expanding the contact area, in contrast to T-WC. This leads to a reduction in maximum pressure, mean pressure, and total seat pressure. Moreover, the center of pressure was more centered and the SI of P-WC was closer to 0 than that of T-WC. The lateral support provided by the backrest shape of $\mathrm{P}-\mathrm{WC}$ also affects the seat plane. Proper support of the trunk leads to a reduction in upper body bend, and has the effect of reducing the high pressure of the seat plane or the asymmetrical pressure of the ischial tuberosities.

One of the main wheelchair-related complications is the development of pressure ulcers on the ischium and coccyx due to poor self-care and long-term sitting [46,47]. In addition, although strong evidence on prevention of pressure ulcers has not been established,

Table 2. Pressure data.

\begin{tabular}{|c|c|c|c|c|c|c|c|}
\hline \multirow{2}{*}{\multicolumn{3}{|c|}{ Measured variables }} & \multicolumn{2}{|c|}{ T-WC } & \multicolumn{2}{|c|}{ P-WC } & \multirow{3}{*}{$\begin{array}{c}\mathrm{p} \text {-value } \\
\text { ns }\end{array}$} \\
\hline & & & \multirow{2}{*}{$\begin{array}{c}\text { median } \\
161.2\end{array}$} & \multirow{2}{*}{$\begin{array}{c}\text { quartile } \\
39.87\end{array}$} & \multirow{2}{*}{$\begin{array}{c}\text { median } \\
132.3\end{array}$} & \multirow{2}{*}{$\begin{array}{c}\text { quartile } \\
52.06\end{array}$} & \\
\hline \multirow{2}{*}{\multicolumn{2}{|c|}{ Maximum pressure (mmHg) }} & Seat plane & & & & & \\
\hline & & Backrest plane & 30.9 & 25.65 & 37.4 & 14.40 & ns \\
\hline \multirow{2}{*}{\multicolumn{2}{|c|}{ Average pressure (mmHg) }} & Seat plane & 41.1 & 4.79 & 35.5 & 10.27 & $<0.01$ \\
\hline & & Backrest plane & 7.5 & 4.30 & 6.9 & 2.40 & ns \\
\hline \multirow{2}{*}{\multicolumn{2}{|c|}{ Sensing area $\left(\mathrm{cm}^{2}\right)$}} & Seat plane & 1345.3 & 87.41 & 1339.6 & 68.90 & ns \\
\hline & & Backrest plane & 201.0 & 96.09 & 468.6 & 136.08 & $<0.01$ \\
\hline \multirow{2}{*}{\multicolumn{2}{|c|}{ Total pressure $\left(\mathrm{mmHg}^{*} \mathrm{~cm}^{2} / \mathrm{kg}\right)$}} & Seat plane & 959.4 & 225.99 & 814.4 & 201.24 & $<0.01$ \\
\hline & & Backrest plane & 35.5 & 23.61 & 54.2 & 14.70 & $<0.05$ \\
\hline \multirow{4}{*}{ Position $(\mathrm{cm})$} & \multirow{2}{*}{ Horizontal center } & Seat plane & 22.9 & 0.88 & 21.8 & 1.12 & $<0.01$ \\
\hline & & Backrest plane & 20.3 & 1.08 & 21.4 & 1.77 & $<0.01$ \\
\hline & \multirow{2}{*}{ Vertical center } & Seat plane & 21.8 & 1.21 & 23.3 & 1.33 & $<0.05$ \\
\hline & & Backrest plane & 12.9 & 3.92 & 21.6 & 11.04 & $<0.05$ \\
\hline \multicolumn{3}{|c|}{ Symmetry index (\%) } & 22.6 & 15.82 & 7.1 & 18.36 & $<0.05$ \\
\hline
\end{tabular}

Table 3. Measurements of posture alignments.

\begin{tabular}{|c|c|c|c|c|c|c|c|}
\hline \multirow{2}{*}{\multicolumn{3}{|c|}{ Measured variables }} & \multicolumn{2}{|c|}{ T-WC } & \multicolumn{2}{|c|}{ P-WC } & \multirow{3}{*}{$\begin{array}{c}\text { p-value } \\
\text { ns }\end{array}$} \\
\hline & & & \multirow{2}{*}{$\begin{array}{c}\text { median } \\
72.3\end{array}$} & \multirow{2}{*}{$\begin{array}{c}\text { quartile } \\
4.95\end{array}$} & \multirow{2}{*}{$\begin{array}{c}\text { median } \\
70.0\end{array}$} & \multirow{2}{*}{$\begin{array}{c}\text { quartile } \\
3.38\end{array}$} & \\
\hline \multirow{6}{*}{ Sagittal plane } & \multirow{2}{*}{ Head inclination } & Paretic & & & & & \\
\hline & & Non-paretic & 74.6 & 5.15 & 71.7 & 4.58 & ns \\
\hline & \multirow{2}{*}{ Neck inclination } & Paretic & 43.9 & 9.00 & 39.5 & 4.40 & $<0.05$ \\
\hline & & Non-paretic & 44.9 & 10.45 & 41.2 & 3.88 & $<0.05$ \\
\hline & \multirow{2}{*}{ Trunk inclination } & Paretic & 105.2 & 5.40 & 116.5 & 5.15 & $<0.01$ \\
\hline & & Non-paretic & 105.9 & 4.40 & 117.7 & 6.33 & $<0.01$ \\
\hline \multirow{4}{*}{ Frontal plane } & \multicolumn{2}{|c|}{ Head lateral inclination } & 3 & 2.83 & 2.3 & 3.0 & ns \\
\hline & \multicolumn{2}{|c|}{ Neck lateral inclination } & 5.1 & 3.50 & 3.9 & 2.13 & ns \\
\hline & \multicolumn{2}{|c|}{ Trunk lateral inclination } & 1.5 & 1.28 & 1.3 & 1.60 & ns \\
\hline & \multicolumn{2}{|c|}{ Acromial tilt } & 1.3 & 1.65 & 0.9 & 0.68 & ns \\
\hline
\end{tabular}


it has been suggested that the high pressure leads to risk of pressure ulcers $[48,49]$. It would be interesting to envisage that the altered shape of the backrest that defocuses the seat surface pressure may help reduce the risk of ulcers, although further analyses are necessary.

The differences in backrest shape between T-WC and P-WC also affected postural alignments. On P-WC, upright head-neck alignment and backward inclination of the trunk were observed. This supports the results of a previous study that the new P-WC eliminated a forward head posture and expanded cervical movement $[29,30]$. From a kinematic perspective, the mass of the head, neck, and trunk accounts for $64.4 \%$ of total body weight [50], and this mass is positioned forward relative to the spine when seated upright. This mass generates a forward torque because of the structural incompatibility between the natural thoracic curvature and the flat supporting surface of the T-WC backrest. Furthermore, elderly patients with stroke tend to take a forward head posture $[51,52]$. The burden on the musculoskeletal system decreases as the head and neck approaches the neutral position, and a neutral head position contributes to postural adjustment against gravity $[53,54]$. Keeping the head neutral for patients with subacute stroke could be the basis of the re-perception of an internal vertical axis and improvement of sitting posture.

In addition, optimal conditions concerning disc pressure and muscular activity were obtained when the backrest was inclined to $110^{\circ}$ or $120^{\circ}$ from the horizontal position [55]. In a wheelchair-seated posture, $\mathrm{P}-\mathrm{WC}$ meets this range. Although simple reclining was related to the problem of forward sliding [56], the backrest shape of the P-WC corresponds to the spinal curve, and this feature helps prevent forward sliding by receiving upper body mass properly.

The present study showed that in the frontal plane, no significant differences in postural alignment were observed. However, the head, neck, and trunk tended to be closer to the center of body axis in P-WC. Study of postural orientation in the frontal plane in wheelchairs is limited, so further investigation will be needed.

\section{Study limitations}

The generalizability of these results may be limited by the small number of subjects enrolled in this non-mobile study. Subjects had only mild hemiparesis and were capable of relatively high trunk function that allowed them to move to the wheelchair with little assistance. Therefore, it is unknown whether the results would transfer to real life (e.g., wheelchair propulsion) or whether the outcomes would be the same in severely disabled hemiparesis patients. Moreover, pressure and postural change were not evaluated over a long term; implications of long-term usage are therefore unknown. Furthermore, the belts were not adjusted for each individual because tension adjustments could affect the results of our study. Therefore, we did not conduct the investigation on how tension adjustment affected individuals (e.g., strength of the contact pressure). In another wheelchair configuration study for stroke, patients with flaccid hemiplegia were more affected by the shape of wheelchair than were those with spastic hemiplegia [57]. We believe that future long-term studies including elderly patients with hemiparesis with poor trunk muscular strength are necessary.

\section{Conclusion}

Backrest shape affects seated pressure and sitting postural alignment. Compared with conventional wheelchairs, a wheelchair with pelvic and thoracic support belts is expected to decrease the burden on the musculoskeletal system by promoting the upright alignment of the head-neck and backward inclination of the trunk.
In addition, the asymmetrical pressure that characterizes the sitting patterns of stroke patients was alleviated in the center of pressure points, and SI values improved, demonstrating that the backrest shape with pelvic and thoracic support belts had the effect of reducing patient asymmetry. When prescribing wheelchairs, more attention should be paid to backrest shape in addition to the seat surface.

\section{References}

1. Thorvaldsen P, Asplund K, Kuulasmaa K, Rajakangas AM, Schroll M (1995) Stroke incidence, case fatality, and mortality in the WHO MONICA project. World Health Organization Monitoring Trends and Determinants in Cardiovascular Disease. Stroke 26: 361-367. [Crossref]

2. WHO (2014) World health statistics 2014. Geneva. Pp: 45-47.

3. Tyson SF, Hanley M, Chillala J, Selley AB, Tallis RC (2007) The relationship between balance, disability, and recovery after stroke: predictive validity of the Brunel Balance Assessment. Neurorehabil Neural Repair 21: 341-346. [Crossref]

4. Laufer Y, Sivan D, Schwarzmann R, Sprecher E (2003) Standing balance and functiona recovery of patients with right and left hemiparesis in the early stages of rehabilitation. Neurorehabil Neural Repair 17: 207-213. [Crossref]

5. Nichols DS (1997) Balance retraining after stroke using force platform biofeedback. Phys Ther 77: 553-558. [Crossref]

6. Mizrahi J, Solzi P, Ring H, Nisell R (1989) Postural stability in stroke patients: vectorial expression of asymmetry, sway activity and relative sequence of reactive forces. Med Biol Eng Comput 27: 181-190. [Crossref]

7. Johannsen L, Broetz D, Karnath HO (2006) Leg orientation as a clinical sign for pusher syndrome. BMC Neurol 6: 30. [Crossref]

8. Vearrier LA, Langan J, Shumway-Cook A, Woollacott M (2005) An intensive massed practice approach to retraining balance post-stroke. Gait Posture 22: 154-163. [Crossref]

9. Dickstein R, Abulaffio N (2000) Postural sway of the affected and nonaffected pelvis and leg in stance of hemiparetic patients. Arch Phys Med Rehabil 81: 364-367. [Crossref]

10. Tanaka S, Hachisuka K, Ogata H (1997) Trunk rotatory muscle performance in poststroke hemiplegic patients. Am J Phys Med Rehabil 76: 366-369. [Crossref]

11. Tanaka S, Hachisuka K, Ogata H (1998) Muscle strength of trunk flexion extension in post-stroke hemiplegic patients. Am J Phys Med Rehabil 77: 288-290. [Crossref]

12. Winzeler-Merçay U, Mudie H (2002) The nature of the effects of stroke on trunk flexor and extensor muscles during work and at rest. Disabil Rehabil 24: 875-886. [Crossref]

13. Dickstein R, Shefi S, Marcovitz E, Villa Y (2004) Electromyographic activity of voluntarily activated trunk flexor and extensor muscles in post-stroke hemiparetic subjects. Clin Neurophysiol 115: 790-796. [Crossref]

14. Teasell RW, Foley NC, Bhogal SK, Chakravertty R, Bluvol A (2005) A rehabilitation program for patients recovering from severe stroke. Can J Neurol Sci 32: 512-517. [Crossref]

15. Mann WC, Llanes C, Justiss MD, Tomita M (2004) Frail older adults' self-report of their most important assistive device. OTJR 24: 4-12

16. Mortenson WB, Oliffe JL, Miller WC, Backman CL (2012) Grey spaces: the wheeled fields of residential care. Sociol Health Illn 34: 315-329. [Crossref]

17. Green G, Young J (2011) The provision of wheelchairs for older people in the United Kingdom. Eur Geriatr Med 2: 52-55.

18. Cherubini M, Melchiorri G (2012) Descriptive study about congruence in wheelchair prescription. Eur J Phys Rehabil Med 48: 217-222. [Crossref]

19. Shaw G, Taylor SJ (1991) A survey of wheelchair seating problems of the institutionalized elderly. Assist Technol 3: 5-10. [Crossref]

20. Giesbrecht EM, Mortenson WB, Miller WC (2012) Prevalence and facility level correlates of need for wheelchair seating assessment among long-term care residents. Gerontology 58: 378-384. [Crossref]

21. van Nes IJ, Nienhuis B, Latour H, Geurts AC (2008) Posturographic assessment of sitting balance recovery in the subacute phase of stroke. Gait Posture 28: 507-512. [Crossref]

22. Cirstea MC, Levin MF (2000) Compensatory strategies for reaching in stroke. Brain 123: 940-953. [Crossref] 
23. Dean CM, Shepherd RB (1997) Task-related training improves performance of seated reaching tasks after stroke: a randomized controlled trial. Stroke 28: 722-728. [Crossref]

24. Sandin KJ, Smith BS (1990) The measure of balance in sitting in stroke rehabilitation prognosis. Stroke 21: 82-86. [Crossref]

25. Nichols DS, Miller L, Colby A, Pease WS (1996) Sitting balance: its relation to function in individuals with hemiparesis. Arch Phys Med Rehabil 77: 865-869. [Crossref]

26. Lee IH, Park SY (2011) Assistive cushions for symmetric wheelchair sitting by stroke patients. J Phys Ther Sci 23: 837-840.

27. Nishimura S (2013) Science of the wheelchair and humans. Description of pelvis support model in active balance seating. Hokkaido J Occup Ther 30: 8-20.

28. Nishimura S (2013) Science of the wheelchair and humans. Description of thorax support model in active balance seating. Hokkaido J Occup Ther 30: 21-31.

29. Ukita A, Nishimura S, Kishigami H, Hatta T (2015) Backrest Shape Affects Head-Neck Alignment and Seated Pressure. J Healthc Eng 6: 179-192. [Crossref]

30. Sawada N, Hatta T, Kishigami H, Shimizu M, Yoda T, et al. (2015) The effect of a newly developed wheelchair with thoracic and pelvic support on cervical movement and muscle activity in healthy elderly women. Eur Geriatr Med 6: 286-290.

31. Brunnstrom S (1970) Movement Therapy in Hemiplegia: A Neurophysiological Approach. New York: Medical Dept., Harper \& Row.

32. Straker LM, O'Sullivan PB, Smith AJ, Perry MC, Coleman J (2008) Sitting spinal posture in adolescents differs between genders, but is not clearly related to neck shoulder pain: an observational study. Aust J Physiother 54: 127-133. [Crossref]

33. Parent F, Dansereau J, Lacoste M, Aissaoui R (2000) Evaluation of the new flexible contour backrest for wheelchairs. J Rehabil Res Dev 37: 325-333. [Crossref]

34. Ferguson-Pell M, Cardi MD (1993) Prototype development and comparative evaluation of wheelchair pressure mapping system. Assist Technol 5: 78-91. [Crossref]

35. Dey ZR, Nair NR, Shapcott N (2013) Evaluation of the Force Sensing Application pressure mapping system. J Med Eng Technol 37: 213-219. [Crossref]

36. Miller SK, Aberegg L, Blasiole K, Parker M, Fulton J (2014) A prospective assessment of sacral pressures in healthy volunteers seated upright and reclined with legs elevated in a recliner. Ostomy Wound Manage 60: 52-59. [Crossref]

37. Kim WJ, Chang M (2013) A comparison of the average sitting pressures and symmetry indexes between air-adjustable and foam cushions. J Phys Ther Sci 25: 1185-1187. [Crossref]

38. Bonnaire R, Verhaeghe M, Molimard J, Calmels P, Convert R5 (2014) Characterization of a pressure measuring system for the evaluation of medical devices. Proc Inst Mech Eng H 228: 1264-1274. [Crossref]

39. Borel S, Schneider P, Newman CJ (2011) Video analysis software increases the interrater reliability of video gait assessments in children with cerebral palsy. Gait Posture 33: 727-729. [Crossref]

40. Constand MK, MacDermid JC (2013) Effects of neck pain on reaching overhead and reading: a case-control study of long and short neck flexion. BMC Sports Sci Med Rehabil 5: 21. [Crossref]
41. van Niekerk SM, Louw Q, Vaughan C, Grimmer-Somers K, Schreve K (2008) Photographic measurement of upper-body sitting posture of high school students: reliability and validity study. BMC Musculoskelet Disord 9: 113. [Crossref]

42. Linder-Ganz E, Scheinowitz M, Yizhar Z, Margulies SS, Gefen A (2007) How do normals move during prolonged wheelchair-sitting? Technol Health Care 15: 195-202. [Crossref]

43. Pérennou D, Piscicelli C, Barbieri G, Jaeger M, Marquer A, et al. (2014) Measuring verticality perception after stroke: why and how? Neurophysiol Clin 44: 25-32. [Crossref]

44. Kuo YL, Tully EA, Galea MP (2009) Video analysis of sagittal spinal posture in healthy young and older adults. J Manipulative Physiol Ther 32: 210-215. [Crossref]

45. Milette D, Rine RM (1987) Head and trunk movement responses in healthy children to induced versus self-induced lateral tilt. Phys Ther 67: 1697-1702. [Crossref]

46. Sumiya T, Kawamura K, Tokuhiro A, Takechi H, Ogata H (1997) A survey of wheelchair use by paraplegic individuals in Japan. Part 2: Prevalence of pressure sores. Spinal Cord 35: 595-598. [Crossref]

47. Collins F (2001) Sitting: pressure ulcer development. Nurs Stand 15: 54-58. [Crossref]

48. Sprigle S, Sonenblum S (2011) Assessing evidence supporting redistribution of pressure for pressure ulcer prevention: a review. J Rehabil Res Dev 48: 203-213. [Crossref]

49. Taule T, Bergfjord K, Holsvik EE, Lunde T, Stokke BH, et al. (2013) Factors influencing optimal seating pressure after spinal cord injury. Spinal Cord 51: 273-277. [Crossref]

50. Greene DP, Roberts SL (2005) Kinesiology: Movement in the Context of Activity (2ndedn). St. Louis: Elsevier Mosby.

51. Yukawa Y, Kato F, Suda K, Yamagata M, Ueta T (2012) Age-related changes in osseous anatomy, alignment, and range of motion of the cervical spine. Part I: Radiographic data from over, 200 asymptomatic subjects. Eur Spine J 21: 1492-1498. [Crossref]

52. Park MS, Moon SH, Lee HM, Kim SW, Kim TH, et al. (2013) The effect of age on cervical sagittal alignment: normative data on 100 asymptomatic subjects. Spine (Phila $\mathrm{Pa}$ 1976) 38: E458-E463. [Crossref]

53. Morningstar MW, Pettibon BR, Schlappi H, Schlappi M, Ireland TV (2005) Reflex control of the spine and posture: a review of the literature from a chiropractic perspective. Chiropr Osteopat 13: 16. [Crossref]

54. Treleaven J (2008) Sensorimotor disturbances in neck disorders affecting postura stability, head and eye movement control. Man Ther 13: 2-11. [Crossref]

55. Kroemer KHE, Grandjean E (1997) Fitting the task to the human: A textbook of occupational ergonomics. ( $5^{\text {th }}$ edn). Philadelphia: Taylor \& Francis.

56. Huang HC, Yeh CH, Chen CM, Lin YS, Chung KC (2011) Sliding and pressure evaluation on conventional and $\mathrm{V}$-shaped seats of reclining wheelchairs for stroke patients with flaccid hemiplegia: a crossover trial. J Neuroeng Rehabil 8: 40. [Crossref]

57. Huang HC, Lin YS, Chen JM, Yeh CH, Chung KC (2013) The impact of abnorma muscle tone from hemiplegia on reclining wheelchair positioning: a sliding and pressure evaluation. Eur J Phys Rehabil Med 49: 619-628. [Crossref]

Copyright: (C2017 Ukita A. This is an open-access article distributed under the terms of the Creative Commons Attribution License, which permits unrestricted use, distribution, and reproduction in any medium, provided the original author and source are credited. 